\title{
Understanding the Relationship of land uses and water quality in Twenty First Century: A Review \\ Subhasis Giri* Zeyuan Qiu
}

\author{
Department of Chemistry and Environmental Science, New Jersey Institute of Technology, \\ University Heights, Newark, NJ 07102, USA \\ *Corresponding author: Tel: +1(973-596-5284) Fax: +1(973)-596-3586 \\ Email: subhasis.giri@njit.edu (Subhasis Giri)
}

\begin{abstract}
Rising food, housing and energy demand of increasing population creates an immense pressure on water resources, especially on water quality. The water quality around the globe is degrading primarily due to intense agricultural activities associated with rapid urbanization. This study attributes to cause of water quality problem, indices to measure water quality, methods to identify proper explanatory variables to water quality and it's processing to capture the special effect, and finally modeling of water quality using identified explanatory variables to provide insights. This would help policymakers and watershed managers to take necessary steps to protect water quality for the future as well as current generation. Finally, some knowledge gaps are also discussed which need to be addressed in the future studies.
\end{abstract}

\section{Introduction}

Water quality is defined as a measure that can evaluate the usage of water for different purposes (drinking, agricultural, industrial, recreational, and habitat) using various parameters such as physical, chemical, and biological. Water quality plays a pivotal role in all aspects of living organisms in the earth which entices attention of environmental scientists, ecologist, hydrologist, watershed managers, and agricultural scientists. Water quality varies based on location, time, weather, and presence of pollution sources. Maintaining proper water quality is challenging task primarily due to presence of point and non-point sources (NPS) of pollution. Point source is confined, easily identifiable and is regulated by the different state and Federal agencies (USEPA, 2009). However, NPS pollution is difficult to identify due to complex and diffuse nature of interaction between runoff and landscape (Chiwa et al., 2012, Carpenter et al., 1998).

Land use is one of the components of landscape which has a vital role in generation of pollution. Increase in population changes land use primarily due to 1) need of housing, 2) food for life, and 3) development of infrastructure for easy transportation which fosters urbanization and agricultural activities. Urbanization increases impervious surface such as parking lots, roof tops, roads, and sidewalks resulting into increase in runoff which creates additional avenue for transportation of pollutants from landscape into waterbodies (Wilson and Weng, 2010). On the other hand, agricultural activities increases amount of fertilizers, pesticides, herbicides, and dairy manures in the cropland to fulfill the food demand of human population and some of those enters into the nearest waterbodies. Direct and indirect impact of urbanization and agricultural activities degrade water quality (Yu et al., 2013) which is the consequences of land use change.

Degradation of water quality increases algal bloom and phytoplankton biomass, taste and odor of water, and drinking water purification cost (Tsegaye et al., 2006) which ultimately creates 
negative impact on both terrestrial and aquatic ecosystems (Zhang et al., 2012). For example, increase in suspended solids increases turbidity in water reducing lesser light penetration into waterbodies, which has a detrimental effect on fish and other aquatic animals due to lesser photosynthesis (Giri, 2013).

Finding solutions to above mentioned problems as well as other environmental issues is based on following factors: i) providing environmental education, ii) forming environmental legislation, iii) use of new technology, and iv) environmental awareness by corporates, and v) acceptance of technology by society. Environmental education is one of the solutions to sustainable development both in developed and developing countries. Environmental education provides direction to human behavior towards nature and promotes environmental ethics. One of the method to introduce environmental education is by introducing environmental courses both in primary and higher educational institution as well as engaging students in different extracurricular activities such as planting of trees. This creates awareness among the students and promotes positive attitude towards environment. For example, Rangel et al. (2015) conducted a study in Marine Beach at South coastal of Portugal in an effort to reduce negative ecological impacts during snorkeling by enhancing public awareness. They found that on site education and interpretation would be able to reduce negative ecological impacts. Simsekli (2015) examined the effect of environmental education practices on elementary school students in Turkey. The students were taught regarding importance of water resources, water pollution and its effect for two hours a week for two weeks. They compared the same open ended question before and after the two weeks course among the same students and observed that environmental education increased awareness among the students. Erdogan (2011) assessed the ecology based education program on 64 elementary school student in Ankara, Turkey. He found that the education program had significantly positive impact towards the students' environmental behavior.

Second pillar to mitigate environmental issue is the environmental regulatory frame work by governmental agencies. Yin et al.(2015) performed a study to determine the effect of environmental regulation in reducing $\mathrm{CO}_{2}$ emmision in China. They found that environmental regulation had significant impact on decreasing $\mathrm{CO}_{2}$ emission. Another study, by Zhao et al.(2015) also found that environmental regulation helps different companies (such as electric power, steel, and iron) to introduce more greener technology to improve environmental condition. Ford et al.(2014) evaluated the effect of environmental regulation on oil and gas industry in Australia. They found that collaborative regulatory frame work spurs innovation which can address environmental concern. For example, Murphy Pipe and Civil developed a high quality water and sewer pipe against an electric cable which has minimal environmental impact.

Third factor to address environmental issues and maintain a sustainable growth both in developed and developing countries is development of new technology. Technology improves the quality of life whether it may be introducing new medical equipment or providing clean water and electricity to people. The example of new technology that helps our society in water resources is Geographic Information Systems (GIS). We use this technology in different field of water resources such as study of scarcity of water resources, water pollution, domestic and industrial water demands, and food security. Wang et al.(2015) used GIS to delineate aquatic 
ecoregion in the Heihe River Basin in China for policy and management decisions to address water scarcity as well as severe water pollution. Another example of technological advancement solving water resource demand is application of physically based computer model for simulation of water quantity and quality. Sharma et al.(2015) used a physically based hydrological model to predict the water quantity in Giri Watershed which was one of the source of drinking water to the Shimla City in India. This research work provided solution to increasing drinking water demand.

The fourth pillar to address environmental issue is the social pro-activeness by corporates. Increasing awareness in environmental, social, and governance has prompted increase in corporate social responsibility which is designed to implement strategies or principles lead to sustainable development (Ortas et al., 2015). In response to this call, many corporates have incorporated environmental factor in their business agenda. For example, KPMG is actively involved in environmental programs such as developing ISO14001 certification (Mazurkiewich, 1998) which controls business activities that has a tremendous impact on environment. Another example would be Bhopal gas leak tragedy in India which created Responsible Care Program in chemical industries. This is a self-regulatory program that sets code of conduct against lack of government regulation. This improved the environmental condition and overall performance of the companies (Gamper-Rabindran and Finger, 2013).

The fifth factor to address environmental challenges is acceptance of technology in the society. Introduction of technology into grass root level (producers or farmers) needs formation of supporting institutions with technologically educated work force. Chhetri et al.(2012) studied the involvement of multilevel institutions including farmers and non-governmental organization in developing location specific solution to agricultural adaption to mitigate climate change in Nepal. They found that involvement of farmers and other non-governmental organization facilitate adaptation of new technology in the society. Adenle et al.(2015) examined the innovation and diffusion of technology in agriculture in order to address climate change in developing countries. They suggested that collaborative approach with farmers during the process of identifying best solution would foster the implementation of technology to tackle climate change in agriculture.

This paper examines the third factor which is development of new technology in the field of water resources, specifically, recent developments in land use and water quality both in developing and developed countries.

Assessment of relationship between land use and water quality is of great importance to protect fresh water, which would fulfill the water demand in different sectors such as increased agricultural activities, industrial usage, municipal usage, supply of drinking water, and recreational use. Additionally, understanding the relationship between land use and water quality would help assessing the water quality in the unmonitored watershed as monitoring is expensive and time consuming. Also, this knowledge would provide guideline to watershed managers and policymakers to prioritize the future land use development in the rapidly urbanizing world. Therefore, this requires a thorough understanding of advantage and disadvantage of techniques applied, scale of study area, focus of land use metrics, and relationship observed by different studies. The motivation for this research work is due to increase in land use changes by 

knowledge gaps.

anthropogenic activities such as intensive agriculture, rapid urbanization, and deforestation in developed as well as developing countries.

The objective of this study is to review the fundamental relationship between land use and water quality as well as the recent developments in this area. This paper is presented as follows. Section 1 entails a brief description of water quality, source of pollutions, land use, factors affecting land use change and its effect, impact of water quality degradation, factors to address environmental issues, and importance of understanding the relationship between land use and water quality, section 2 presents a conceptual visualization of water quality assessment, section 3 reviews factors affecting water quality degradation, section 4 describes about the indices to measure water quality, section 5 presents indices to process explanatory variables to water quality, section 6 entails techniques to analyze water quality problem, section 7 depicts determination of water quality explanatory variables, section 8 presents water quality and land use study around the globe, and section 9 tells about the conclusion of this study along with some

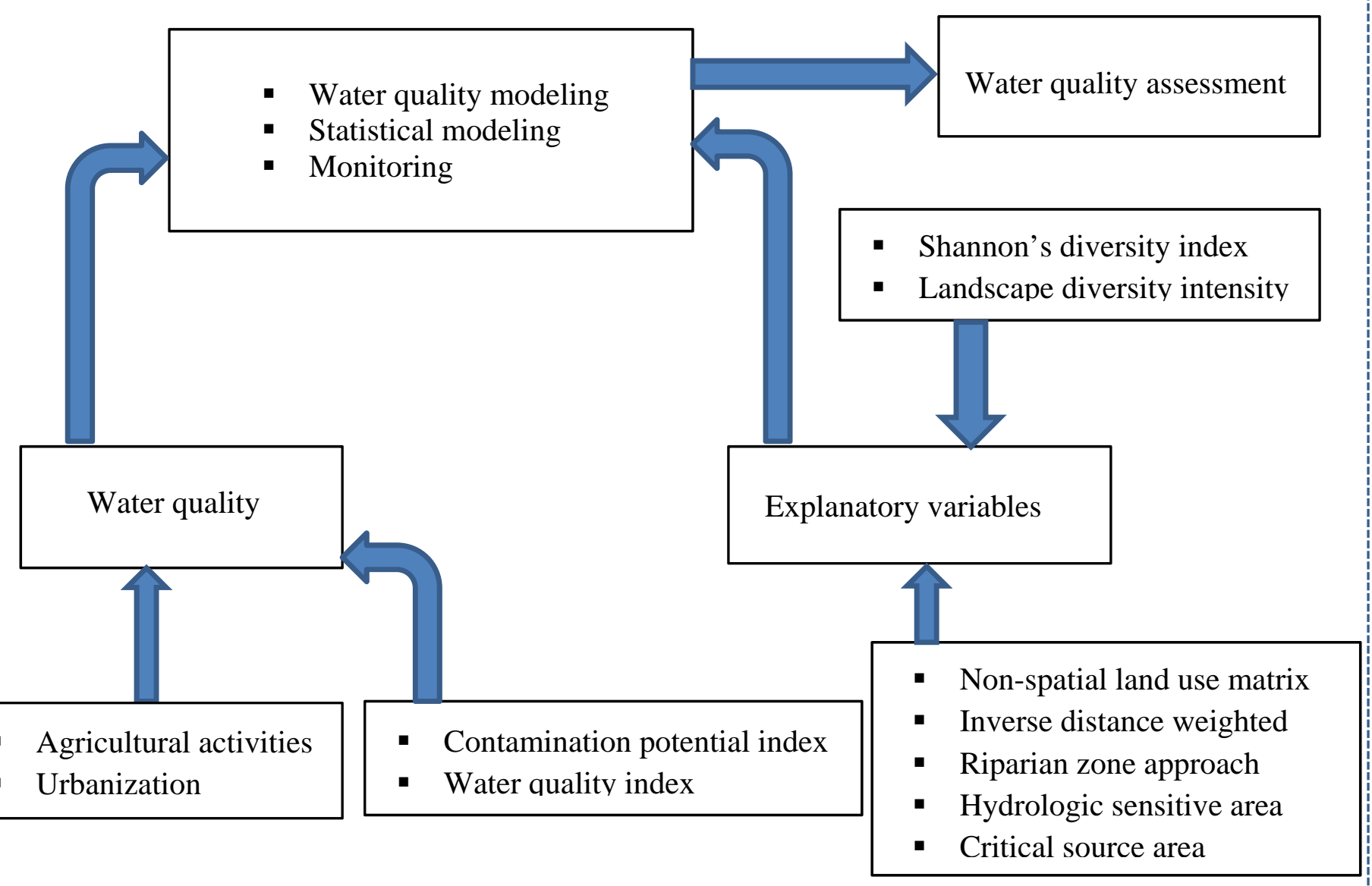

Fig. 1. Schematic visualization of water quality assessment in recent studies. 


\section{Conceptual visualization of Water quality assessment}

The conceptual visualization of water quality assessment up to recent times is provided in Figure 1. Water quality is primarily degraded due to agricultural activities and urbanization and is categorized into impaired or unimpaired based on the indicator such as contamination potential index or water quality index. The water quality explanatory variables are determined using different techniques such as non-spatial land use matrix, riparian zone approach, hydrologic sensitive area, critical source area and are processed using different indices to capture special behavior towards water quality. The selected water quality explanatory variables are further processed using either hydrologic/water quality model or statistical modeling or monitoring data to determine the source and cause of water quality degradation. Based on the water quality assessment, further watershed managers and policymakers are informed and this assessment facilitates them to take corresponding course of action to protect water quality. The detail description of the each of the component in the schematic diagram is presented below.

\section{Factors affecting water quality degradation}

Out of point and non-point source pollutions, NPS pollution is a great concern due to its complex nature. Specifically, NPS pollution from increased agricultural activities and urbanization has drawn attention of both scientific communities as well as regulatory agencies due to increasing demand of food and housing to increased population in the world. Detail descriptions of both factors are provided below:

\subsection{Impact of Agricultural activities on water quality}

Different agricultural activities degrade water quality directly or indirectly. For example, improper agricultural practices such as excessive plowing disturb the soil particles and these soil particles enter into nearest waterbodies through soil erosion in runoff. Increase sediment concentration/load reduces oxygen level in water as well as changes water temperature which resulted into an unfavorable ambience to aquatic organism (Malone, 2009). Excessive application of fertilizer, manure, and pesticides for better crop production as well as crop protection can be harmful. For example, excessive nitrogen and phosphorus from agricultural fields enters in waterbodies through runoff and increased in these nutrient content accelerate eutrophication resulting into death of fish and other aquatic organisms (Carpenter, 2008).

\subsection{Impact of Urbanization on water quality}

Water quality affects due to human interference under the banner of urbanization such as industrialization and increase in housing (Li et al., 2015). Urbanization alters physical landscape as well as increases impervious surface area which alters watershed hydrology resulting into negative effect on stream water quality and ultimately exacerbates stream integrity (Kennen et al., 2010).

\section{Indices to measure water quality}


CPI is a parameter to quantify the effect of any activity producing toxic and hazardous material and is estimated as the product of quantity of waste material and hazard index (Seeboonruang, 2012). The quantity of waste material depends on flow rate and contamination area while hazard index is determined by toxic material composition and concentration compared to standard. This method estimates a score which lower limit is 0 and upper limit is 100 . The major drawback of this technique is applicability to NPS pollutions, as the diffusive and complex nature of NPS pollutions in the landscape make difficult to estimate correct flow rate and contamination area. However, this method is more preferable to point source pollutions such as industrial discharge.

\subsection{Water quality index (WQI)}

WQI is an indicator through which water quality is assessed quantitatively. It generates a single score by combining sub-index value of each concern pollutant (Fox, 2014). This single score enables general public as well as policymakers, and watershed managers to understand the condition of the environment without having a thorough knowledge about it. The calculation of WQI consists of four steps, 1) selecting a set of variables to describe the water quality, 2) variables of different unit are converted into same scale, 3) variables are assigned weights based on their relative importance to water quality, and 4) generating the WQI using either weighted aggregation or unweighted aggregation method (Feng et al., 2015).

\section{Indices to process explanatory variables to water quality}

Different explanatory variables to water quality are processed using various indices to capture specific behavior of the explanatory variables. For example, landscape intensity index was used to determine the potential impact of land use disturbances. Similarly, Shanon's diversity index was used to address the unpredictability of explanatory variables to water quality. The details of these indices are described below:

\subsection{Shannon's diversity index (SHDI)}

SHDI is the indicator generally uses to assess the effect of land use on water quality which has a capability to examine the heterogeneity of the landscape in different times (Huang et al., 2013). It is one of the common indicator uses by environmental scientist and ecologist. It addresses the multi-collinearity as well as unpredictable behavior of land use metrics (Huang et al., 2013).

\subsection{Landscape development intensity (LDI) index}

LDI index measures the intensity of land use disturbances within a specific area and it requires land use land cover of that area, area of each land use category, energy per time per area for each land use category, and renewable empower intensity of the background area to estimate the LDI index (Carey et ., 2011).

\section{Techniques to analyze water quality problems}

Analysis of water quality is generally performed in three ways 1) Hydrologic/Water quality modeling, 2) Statistical modeling, and 3) monitoring. These techniques are commonly applied for regulatory/policymaking, planning, and exploratory purposes. A comprehensive description of each method is provided below.

\subsection{Hydrologic/Water quality modeling}


Different hydrologic/water quality model such as Soil and Water Assessment Tool (SWAT), Hydrological Simulation Program-Fortran (HSPF), Long-Term Hydrologic and Nonpoint Source Pollution (T-THIA), and Agricultural Nonpoint Source (AGNPS) model has been used to assess the water quality on watershed scale. Out of all the models, SWAT has been used extensively throughout the world to evaluate water quality effect due to its better predicting capacity compared to others. The required model inputs are elevation, land use, soil, management practice, precipitation, temperature, observed streamflow, and water quality data. The model is calibrated and validated based on observed streamflow data and water quality data. The water quality analysis on SWAT could be analyzed based on either subbasin or hydrologic response unit (much smaller than subbasin area) depending on the objective of the study. Furthermore, the water quality analysis can be performed based on either concentration or load of the pollutants. Four targeting methods have developed to perform water quality analysis in SWAT 1) Concentration Impact Index, 2) Load Impact Index, 3) Load per Subbasin Impact Index, and 4) Load per Unit Area Index (Giri et al., 2012).

\subsubsection{Concentration Impact Index (CII)}

CII categorized the stream segment into different pollution level based on the pollutant concentration in the stream (Giri et al., 2012; Tuppad and Srinivasan, 2008). This method is suitable in addressing stream health in the watershed.

\subsubsection{Load Impact Index (LII)}

This method is based on pollutant load in the watershed and classifies based on the principle of

\subsubsection{Load per Subbasin Area Index (LPSAI)}

LASAI is calculated based on the pollutant load from each subbasin (Giri et al., 2012; Tuppad and Srinivasan, 2008) and depicts variation of pollutant load coming from different portion in the watershed. This provides the idea of pollution generation by different combination of land uses in each subbasin.

\subsubsection{Load per Unit Area Index (LPUAI)}

LPUAI is estimated based on pollutant load from unit area of each subbasin (Giri et al., 2012; Tuppad and Srinivasan, 2008). This provides insight into pollution generation from each category of land use.

\subsection{Statistical modeling}

It is simple and an easy to understand method as well as it provides acceptable results. This attracts more researchers and scientific community to use this method instead of complex watershed model which requires intensive input data to support model parametrization, calibration, and validation. The most common statistical techniques use by researchers are described below:

\subsubsection{Ordinary least squares (OLS)}

This method tries to identify the most influential parameters among all the independent variable in the regression equation. More specifically, the coefficients from OLS model provide the most influential parameters of varying water quality (Sun et al., 2014). The advantage of using OLS in 
geographic information system is able to examine the spatial autocorrelation among the residuals (Pratt and Chang, 2012).

\subsubsection{Geographic weighted regression (GWR)}

This technique considers the spatial variation and can be used to determine the relationship between land use and water quality by incorporating coordinates of location into the regression equation. It uses traditional regression to estimate local parameters and GWR weights are assigned based on the principle that observation closer to the sampling site has greater impact compared to the one away from sampling site on local estimate (Huang et al., 2015). The strength of the explanatory variables and water quality parameters is assessed by the local coefficient of GWR model (Sun et al., 2014).

\subsubsection{Bayesian hierarchical linear regression (BHLR)}

This method considers interaction of variables both space and time which enables to perform spatio-temporal modeling framework (Pollice and Lasinio, 2010a). Furthermore, the BHLR can be decomposed into data model, process model, and parameter model (Wan et al., 2014). The data model indicates the distribution of data where the process model describes the regression model, and the parameter model depicts the distribution of parameters. These models are linked through probability relationships (Wikle and Anderson, 2003). This technique was used by Wan et al.(2014) to determine the effect of land use/cover on stream water quality in China.

\subsubsection{Stepwise multiple regression}

In this technique, all the explanatory variables are added into the regression equation and then drop one variable at- a-time until get most improved model and the model is evaluated using model evaluation parameters. In case of water quality analysis, the independent variables with higher correlation with water quality are determined using this technique (Pratt and Chang, 2012). However, for repeated and unequal measures linear mixed model is preferred over multiple regressions.

\subsubsection{Linear mixed effect model}

It considers both fixed effect and random effect where fixed effects are presented by the explanatory variables and the random effect are the interaction between the each location where the explanatory variables are collected. Seilheimer et al.(2013) used this model to determine the most influential land use to phosphorus concentration in the Great lakes in Michigan.

\subsubsection{Partial least square regression (PLSR)}

PLSR is a method to analyze the response variable by using a set of explanatory variables having best predicting power (Abdi, 2010). The PSLR algorithm generates improved prediction results by using most important linear combination (Ai et al., 2015). The PLSR combines output from principal component analysis and multiple linear regressions (Abdi, 2010).

\subsubsection{Principal component analysis (PCA)}

PCA analysis identifies the redundant variables and class levels which tell us whether a reduced set of variables are able to explain the response variable (Amiri and Nakane, 2009). In other 
words, PCA creates smaller set of variables from original variables which explains maximum variance in the dataset (Paul, 2003). In stream water quality analysis, potentially correlated variables that explain water quality are grouped into fewer sets of principal components. These principal components are unrelated with each other.

\subsection{Monitoring}

Monitoring water quality data in the stream is not only important for a healthy ecosystem but also provides knowledge which facilitates timely implementation of corrective measures for sustainable environmental system. However, monitoring is expensive, time consuming, and ineffective for larger area. Therefore, modeling is preferred than monitoring in case of larger study area such as watershed scale.

\section{Identification of water quality explanatory variables}

In order to construct statistical modeling between water quality and explanatory variables, it is foremost important to select appropriate explanatory variables. Different techniques have developed in the recent times to identify right explanatory variables are described below:

\subsection{Non-spatial land use metrics}

Some researchers use non-spatial land use metrics to represent landscape changes and its impact on water quality. For example, percentage of urban area and impervious surface are generally used to reflect the effect of urbanization on stream water quality (Schueler et al., 2009). Some studies found that impervious surface greater than 10 percent in a watershed represents declining stream health whereas impervious surface is equal to 25 percent reflects no longer support of stream for designated usage (Schueler, 1994). This non-spatial indicator holds simple assumption that each part of the landscape has an equal potential to affect stream integrity (Williams et al., 2005) which may be misleading.

\subsection{Inverse distance weighted method}

In this method, the landscape metric closer to stream is assigned more weight compared to the landscape metric located away from the stream while evaluating stream integrity (Peterson et al., 2010). The greater weight to landscape metric based on their location with respective to stream enables to capture activity surrounding stream.

\subsection{Riparian zone approach}

Riparian zone plays a critical role in influencing stream health, as it connects terrestrial landscape with aquatic ecosystem (Gregory et al., 1991). Any activities in the riparian zone pose a stronger influence on water quality and ultimately on stream health (NRC, 2002). Therefore, during assessment of water quality and stream health, landscape change within riparian zone is considered instead of whole watershed landscape (Baker et al., 2007). However, there are some drawbacks in this riparian zone approach: i) absence of uniform way of defining the width of the riparian zone makes it difficult in defining riparian zone and ii) When considering the spatial variability of hydrological connectivity in the watershed, riparian zone does not behave as an ideal example to represent hydrological variation in the landscape.

\subsection{Hydrological sensitive area}


Hydrological sensitivity area is a relatively small portion in the watershed which contributes actively to runoff (Qiu, 2009). This area is the saturated area in the watershed where runoff is independent of rainfall intensity and this hydrological process is called variable source area hydrology (Walter et al., 2000). Incorporation of this variable source area hydrology eliminates riparian zone hydrological connection drawback. This runoff acts as a transport mechanism to the potential pollutants. Therefore, land use within this hydrologic sensitive area plays an important role in understanding the effect of land use change on stream water quality.

\subsection{Critical source area}

423 small hydrologically sensitive area (Qiu, 2009). This is also known as the intersection of hydrologic sensitive area and pollution producing area (Walter et al., 2000). This area is generally smaller than hydrologic sensitive area which generates maximum amount of pollutants in the watershed. The critical source areas can be identified either using four targeting methods (Concentration Impact Index, Load Impact Index, Load per Subbasin Impact Index, and Load per Unit Area Index) in SWAT or by using variable source area hydrology and saturation excess concept depending on the topography of the watershed. The land use within the critical source area is further analyzed in assessing the water quality in the stream.

\section{Water quality and land use study around the globe}

Water quality protection is one of the great challenges human beings are facing both in developed and developing Countries. The impact of degraded water quality is severe which can span many sectors of society including health, economy, and recreational activities. Land use and water quality studies are performed in different parts of the world knowing the importance of water for sustainable development of societies. Some of the studies from different parts of the world are described below:

\subsection{North America}

During last three decade, agricultural landscape of United States has changed significantly. Approximately, 40.2 million acres of land converted to developed uses during 1882 to 2007 (USDA, 2009). Based on the United States of Department of Agriculture, the rate of development of developed area during this period was 1.61 million acres per year (USDA, 2009). Due to change in the physical landscape, the watershed hydrology was changed creating a negative impact on stream water quality. This allured researchers (Lin et al., 2015; Sarkar and Miller, 2014; Pratt and Chang, 2012; Carey et al., 2011; Tran et al., 2010; Tu and Xia, 2008) from different parts of US to conduct the land use and water quality study. Some of the studies looked at landscape change and its effect due to intensive bioenergy crops production to meet energy need using SWAT model. Others have used statistical modeling such as OLS, GWR, stepwise regression model, and PCA to understand the land use effect on water quality. They found a positive correlation between land use change water quality degradation.

\subsection{Europe}

One of the greatest challenges in the $21^{\text {st }}$ Century is providing food to growing population in the scenario of more energy demand driven by water shortage (Godfray et al., 2010). Fulfilling this need drives intensification of limited land use resources which creates a negative impact on ecosystem services (Dunn et al., 2015). In the meanwhile, economic development followed by 
urbanization shrinks the available agricultural land forcing into intensification of agricultural activities in the limited land (Naylor and Falcon, 2010). All these above mentioned reasons are deteriorating the water quality in Europe. Researchers (Meneses et al., 2015; Dunn et al., 2015; Teixeira et al., 2014; Fiquepron et al., 2013; Glavan et al., 2013) have performed a series of studies in Europe to understand the relationship of land use and water quality. Some have developed spatial qualitative approach to identify primary drivers of land use change while others used SWAT model to determine its effect to water quality. Additionally, few people used statistical analysis to draw the relation between land use and water quality.

\subsection{Asia}

Population growth followed by increased agricultural production and industrial growth causing water quality degradation in Asia (Evans et al., 2012). Distribution of waste materials, fertilizers, pesticides, and herbicides to agricultural land act as a source of pollution to waterbodies. For example, the Plain area in China is considered as a grain production base of China ensuring the food security causing environmental concern due to application of 5500 million tons of fertilizers and 170 tons of pesticides per year (Liu et al., 2015). Increasing use of fertilizer associated with poor water management is going to increase nitrogen and phosphates significantly from agriculture both in China and India (Gani and Scrimgeour, 2014). In addition to agricultural pollution, approximately 36 billion tons untreated wastewater from different industries is discharged into waterbodies in China (You et al., 2009). Numerous studies (Seeboonruang, 2012; Huang et al., 2013; Zhao et al., 2015; Liu et al., 2015; Fan and Shibata, 2015; Bu et al., 2014; Kang et al., 2010) have been performed to address this water quality issue. Some of them used physically based SWAT model, some used different statistical models such as multiple linear regression, geographically weighted regression, ordinary least square, spatial lag model, and spatial error model to determine behavior of land use towards pollution generation.

\section{Conclusions}

In this paper we discussed factors affecting water quality, water quality indicators, techniques to analyze water quality problem, identification of proper water quality explanatory variables, and finally water quality problems and studies around the world. This manuscript provides a comprehensive knowledge in the area of land use and water quality study. This is very useful to all the Countries, especially developing Countries facing water quality problem such as India and China. If the policymakers in these Countries want to have an overall idea before implementing any policy to maintain proper water quality, it would be pretty helpful.

1) After reviewing all the manuscripts, we concluded that most researchers have used modeling techniques instead of monitoring to determine the relationship between land use and water quality. In modelling, most of them used statistical modeling compared to physically based modeling due to requirement of large number of input data associated with continuous observation data for model building, calibration, and validation process. On contrary, statistical method is simple, easy to understand, and more efficient than physically based hydrologic/water quality model with limited available observed data (Wan et al., 2014). 
2) Among the statistical models, the simple regression modeling such as ordinary least square, multiple linear regression are simple and robust in estimating explanatory variables, however, the complex relationship between land use and water quality cannot be explained. Nevertheless, combining of statistical methods in geographic information system such as geographically weighted regression can explain complex spatial variation by incorporating coordinate system in the model. Recently, incorporation of Bayesian hierarchical modeling provides the ability to analyze both spatial and temporal variation between land use and water quality.

3) Before using any statistical modeling, the explanatory variables should be identified correctly to reflect the right relationship. All land use in different parts of watershed do not contribute equal amount of pollution to waterbodies. Hence, considering all land uses and assuming that all land uses contribute equally to water pollution may be misleading. Therefore, area generating maximum pollution as well as higher propensity to generate runoff in a watershed should be identified and the corresponding land uses should be modelled to achieve a robust relationship between land use and water quality.

4) Performing a land use/cover study using only one indicator may be misleading. For example, landscape development intensity (LDI) index was used by Carey et al.(2011) to identify the land use variable contributing to nutrient load in the Biscayne Bay Watershed, Florida. The LDI index was negatively correlated to $\mathrm{NO}_{\mathrm{x}}-\mathrm{N}$ load and it may identify land use having conflicting nutrient generation characteristics. Therefore, combination of more than one indicator would eliminate this kind of error. Additionally, this type of index provides an overall picture of watershed pollution generation characteristics, however, it does not tell the specific location within a land use pose threat to water quality.

In this manuscript, we reviewed maximum number of articles related to land use and water quality. However, some manuscripts may be overlooked which may address new aspect of land use and water quality study. Therefore, subsequent contribution can be addressed to the overlooked aspect of this manuscript.

\section{Acknowledgements}

The authors acknowledge the funding support by the USDA National Institute of Food and Agriculture through a Agriculture and Food Research Initiative Competitive Grant (grant number NJW-2011-03976).

\section{References:}


Abdi, H., 2010. Partial least squares regression and projection on latent structure regression (PLS regression). Wiley Interdisciplinary Reviews, Computational Statistics 2, 97-106.

Adenle, A. A., Azadi, H., Arbiol, J., 2015. Global assessment of technological innovation for climate change adaptation and mitigation in developing world. Journal of Environmental Management 161, 261-275.

Ai, L., Shi, Z.H., Yin, W., Huang, X., 2015. Spatial and seasonal patterns in stream water contamination across mountainous watershed: linkage with landscape characteristics. Journal of Hydrology 523, 398-408.

Amiri, B.J., B., Nakane, K., 2009. Modeling the linkage between river water quality and landscape metrics in the Chugoku District of Japan. Water Resource Management 23, 931956.

Baker, M. E., Weller, D.E., Jordan, T.E., 2007. Effects of stream map resolution on measures of riparian buffer distribution and nutrient retention potential. Landscape Ecology 22, 973992.

Bu, H., Meng, W., Zhang, Y., Wan, J., 2014. Relationships between land use patterns and water quality in the Taizi River basin, China. Ecological Indicators 41, 187-197.

Carey, R. O., Migliaccio,K.W., li, Y., Schaffer, B., Kiker, G.A., Brown, M.T., 2011. Land use disturbance indicators and water quality variability in the Biscayne Bay Watershed, Florida. Ecological Indicators 11, 1093-1104.

Carpenter, S.R., 2008. Phosphorus control is critical to mitigating eutrophication. Proceeding of National Academy of Science. USA 105, $11039-11040$.

Carpenter, S.R., Caraco, N.E., Correll, D.L., Howarth, W., Sharpley, A.N., Smith, V.H., 1998. Nonpoint pollution of surface waters with phosphorus and nitrogen. Ecological Application 8, 559 -568.

Chhetri, N., Chaudhary, P., Tiwari, P.R., Yadaw, R.B., 2012. Institutional and technological innovation: understanding agricultural adaptation to climate change in Nepal. Applied Geograpghy 33, 142-150.

Chiwa, M., Onikura, N., Ide, J. K, A., 2012. Impact of N-saturated upland forests on downstream N pollution in the Tatara River Basin, Japan. Ecosystems 15, 230 -241.

Dunn, S.M., Towers, W., Dawson, J.J.C., Sample, J., McDonald, J., 2015. A pragmatic methodology for horizon scanning of water quality linked to future climate and land use scenarios. Land Use Policy 44, 131-144. 
Erdogan, M., 2011. The effects of ecology based summer nature education program on primary school students' environmental knowedge, environmental affect and responsible environmental behavior. Educational Science: Theory and Practice 11(4), 2233-2237.

Evans, A.E.V., Hanjra, M.A., Jiang, Y., Qadir, M., Drechsel, P., 2012. Water pollution in Asia:The urgent need for prevention and monitoring. Global Water Forum, UNESCO. Available at: http://www.globalwaterforum.org/2012/06/09/water-pollution-in-asia-theurgent-need-for-prevention-and-monitoring/. (accessed 08.07.15).

Fan, M., Shibata, H., 2015. Simulation of watershed hydrology and stream water quality under land use and climate change scenarios in Teshio River Watershed, northern Japan. Ecological Indicators 50, 79-89.

Feng, Y., Ling, L., Yanfeng, L., You, Z., Musong, C.,Xigang, X., 2015. A dynamic water quality index model based on functional data analysis. Ecological Indicator 57, 249-258.

Fiquepron, J., Garcia, S., Stenger, A., 2013. Land use impact on water quality: valuing forest service in-terms of the water supply sector. Journal of Environmental Management 126, 113-121.

Ford, j.A., Steen, J., Martie-louise, V., 2014. How environmental regulations affect innovation in the Australian oil and gas industry: going beyond the Porter Hypothesis. Journal of Cleaner Production 84, 204-213.

Fox, D.R., 2014. Probability weighted indices for improved ecosystem report card scoring. Environmetrics 25, 351-360.

Gmper-rabindran, S., Finger, S.R., 2013. Does industry self- regulation reduce pollution? Responsible care in the chemical industry. Journal of Regulatory Economics 43, 1-30.

Gani, A., Scrimgeour, F., 2014. Modeling goverance and water pollution using the institutional ecological framework. Economic Modelling 42, 363-372.

Giri, S., 2013. Assessing best management practices and implementation strategies to improve water quality. A Doctoral Dissertation, Michigan State University, East Lansing, Michigan.

Giri, S., Nejadhashemi, A.P., Woznicki, S.A., 2012. Evaluation of targeting methods for implementation of best management practices in the Saginaw River Watershed. Journal of Environmental Management 103, 24-40.

Glavan, M., Milicic, V., Pintar, M., 2013. Finding options to improve catchment water qualitylessons learned from historical land use situations in a Mediterranean catchment in Slovenia. Ecological Modelling 261, 58-73.

Godfray, H.C.J., Beddington, J.R., Crute, I.R., Haddad, L., Lawrence, D., Muir, J.F., Pretty,J., Robinson, S., Thomas, S.M., Toulmin, C., 2010. Food security: the challenge of feeding 9 billion people. Science 327 (5967), 812-818. 
678

679

680

681

682

683

684 685
Gregory, S.C., Swanson, F.J., McKee, W.A., Cummins, K.W., 1991. An ecosystem perspective of riparian zones. BioScience 42, 540-541.

Huang, J., Huang, Y., Pontius, R. G., Zhang, Z., 2015. Geographically weighted regression to measure spatial variations in correlations between water pollution versus land use in a coastal watershed. Ocean \& Coastal Management 103, 14-24.

Huang, J., Zhan, J., Yan, H., Wu, F., Deng, X., 2013. Evaluation of the impacts of land use on water quality: A case study in the Chaohu lake Basin. The Scientific World Journal 329187, 1-7.

Kang, J.H., Lee, S.W., Cho, K.H., Ki, S.J., Cha, S.M., Kim, J.H., 2010. Linking land use type and stream water quality using spatial data of fecal indicator bacteria and heavy metals in the Yeongsan river basin. Water Research 44, 4143-4157.

Kennen, J.G., Murray, M.R., Beaulieu, K.M., 2010. Determining hydrologic factors that influence stream macroinvertebrate assemblages in the northeastern U.S. Ecohydrology 3, 88-106.

Li, Y., Li, Y., Qureshi, S., Kappas, M., Hubacek, K., 2015. On the relationship between landscape ecological patterns and water quality across gradient zones of rapid urbanization in coastal China. Ecological Modeling 7456, 1-9.

Lin, Z., Anar, M.J., Zheng, H., 2015. Hydrologic and water quality impacts of agricultural land use changes incurred from bioenergy policies. Journal of Hydrology 525, 429-440.

Liu, Y., Long, H., Li, T., Tu, S., 2015. Land use transitions and their effects on water environment in Huang-Huai-Hai plain, China. Land Use Policy 47, 293-301.

Malone, S.J., 2009. Agricultural Nonpoint Source Pollution Management: Water Quality Impacts of Balm Road Treatment Marsh, Hillsborough County, Florida. Master of Science Thesis. University of South Florida, Tampa, Florida.

Mazurkiewicz, P., 1998. Corporate environmental responsibility: Is a common CSR framework possible?. Available at: https://siteresources.worldbank.org/EXTDEVCOMSUSDEVT/Resources/csrframework.pd f. (accessed 06.01.16)

Meneses, B.M., Reis, R., Vale, M.J., Saraiva, R., 2015. Land use and land cover changes in Zezere watershed (Portugal)-Water quality implications. Science of Total Environment 527, 439-447.

National Resources Council (NRC). 2002. Riparian Areas: Functions and Strategies for Management. National Academy Press, Washington DC. 
Naylor, R.L., Falcon, W.P., 2010. Food security in an era of economic volatility. Population and Development Review 36, 693-723.

Ortas, E., Alvarez, I., Jaussaud, J., Garayar, A., 2015. The impact of the institutional and social context on corporate environmental, social, and governance performance of companies committed to voluntary corporate social responsibility initiatives. Journal of Cleaner Production 108, 673-684.

Paul, S., 2003. Bacteria total maximum daily load (TMDL): development and evaluation of a new classification scheme for impaired waterbodies of Texas. Doctoral dissertation, Texas A\&M University, College Station, Texas.

Peterson, E.E., Sheldon, F., Darnell, R., Bunn, S.E., Harch, B.D., 2010. A comparison of spatially explicit landscape representation methods and their relationship to stream condition. Freshwater Biology, doi:10.1111/j.1365-2427.2010.02507.

Pollice, A., Lasinio, G.J., 2010a. A multivariate approach to the analysis of air quality in a high environmental risk area. Environmetrics 21, 741-754.

Pratt, B., Chang, H., 2012. Effects of land cover, topography, and built structure on seasonal water quality at multiple spatial scales. Journal of Hazardous Materials 209, 48-58.

Qiu,Z., 2009. Assessing critical source areas in watersheds for conservation buffer planning and riparian restoration. Environmental Management 44, 968-980.

Rangel, M.O., Pita, C.B., Goncalves, J.M.S., Oliveira, F., Coasta, C., Erzini, K., 2015. Ecotouristic snorkeling routes at Marinha beach (Algarve): environmental education and human impacts. Marine Policy 60, 62-69.

Sarkar, S., Miller, S.A., 2014. Water quality impacts of converting intensively managed agricultural lands to switchgrass. Biomass and Bioenergy 68, 32-43.

Schueler, T.R., 1994. The importance of imperviousness. Watershed Protection Technique 1,100-111.

Schueler, T.R., Fraley-McNeal, L., Cappiella, K., 2009. Is impervious cover still important? Review of recent research. Journal of Hydrologic Engineering 14(4), 309-315.

Seeboonruang, U., 2012. A statistical assessment of the impact of land use on surface water quality indexes. Journal of Environmental Management 101, 134-142.

Seilheimer, T. S., Zimmerman, P.L., Stueve, K.M., Perry, C.H., 2013. Landscape scale modeling of water quality in Lake Superior and Lake Michigan watersheds: how useful are forest based indicators. Journal of Great Lakes Research 39, 211-223. 
Sharma, S.K., kansal, M.L., Tyagi, A., 2015. Resource assessment and strategic planning for improvement of water supply to Shimla city in India using geo-spatial techniques. The Egyptian Journal of Remote Sensing and Space 18, 85-97.

Sun, Y., Guo, Q., Liu, J., Wang, R., 2014. Scale effects on spatially varying relationships between urban landscape patterns and water quality. Environmental Management 54, 271287.

Teixeira, Z., Teixeira, H., Marques, J.C., 2014. Systematic processes of land use/ land cover change to identify relevant driving forces: implications on water quality. Science of the Total Environment 470, 1320-1335.

Tran, C.P., Bode, R.W., Smith, A.J., Kleppel, G. S., 2010. Land use proximity as a basis for assessing stream water quality in New York State (USA). Ecological Indicators 10, 727733.

Tsegaye, T., Sheppardi, D., Islam, K. R., Johnson, A., Tadessei, W., Atalay, A., Marzen, L., 2006. Development of chemical index as a measure of in-stream water quality in response to land use and land cover changes. Water Air and Soil Pollution 174, 161-179.

Tu, J., Xia, Z., 2008. Examining spatial varying relationships between land use and water quality using geographically weighted regression I: model design and evaluation. Science of The Total Environment 407, 358-378.

Tuppad, P., Srinivasan, R., 2008. Bosque River Environmental Infrastructure Improvement Plan: Phase II BMP Modeling Report. Publ. No. TR-313. Texas A\&M Univ., Texas AgriLife Research, College Station, Tex.

U.S. Department of Agriculture (USDA). 2009. Summary Report: 2007 National Resources Inventory: Report to Congress. Available at: http://water.epa.gov/lawsregs/guidance/cwa/305b/upload/2009_05_20_305b_2004report_r eport2004pt1.pdf. (accessed 06.01.15)

U.S. Department of Agriculture (USDA). 2009. Summary Report: 2007 National Resources Inventory, Natural Resources Conservation Service, Washington, DC, and Center for Survey Statistics and Methodology, Iowa State University, Ames, Iowa. 123 pages. Available at: http://www.nrcs.usda.gov/technical/NRI/2007/2007_NRI_Summary.pdf. (accessed 06.01.15).

Walter, M.T., Walter, M.F., Brooks, E.S., Steenhuis, T.S., Boll, J., Weiler, K., 2000. Hydrologically sensitive areas: Variable source area hydrologically implications for water quality risk assessment. Journal of Soil and Water Conservation 3, 277-284.

Wan, R., Cai, S., Li, H., Yang, G., Li, Z., Nie, X., 2014. Inferring land use and land cover impact on stream water quality using a Bayesian hierarchical modeling approach in the Xitiaoxi River Watershed, China. Journal of Environmental Management 133, 1-11. 
Wang, S., Cheng, D., Mao, Z., Liu, C., Yang, S., Wnag, L., 2015. An aquatic ecoregion delineation approach based on GIS and spatial environmental data in Heihe River Basin Northwestern China. Quaternary International 380, 272-281.

Wikle, C.K., Anderson, C.J., 2003. Climatological analysis of tornado report counts using a hierarchical Bayesian spatio-temporal model. Journal of Geophysical research 108.

Williams, M., Hopkinson, Rastetter, C, E., Vallino, J., Claessens, L., 2005. Relationships of land use and stream solute concentrations in the Ipswich River basin, Northeastern Massachusetts. Water, Air, and Soil Pollution 161, 55-74.

Wilson, C., Weng, Q., 2010. Assessing surface water quality and its relation with urban land cover changes in the Lake Calumet area, Greater Chicago. Environmental Management 45, 1096-1111.

Sharma, S.K., Kansal, M.L., Tyagi, A., 2015. Resource assessment and strategic planning for improvement of water supply to Shimla city in India using geo-spatial techniques. The Egyptian Journal of Remote Sensing and Space Sciences 18, 85-97.

Simsekli,Y., 2015. An implementation to raise environmental awareness of elementary education students. Procedia- Social and Behavioral Sciences 191, 222-226.

Yin, J., Zheng, M., Chen, J., 2015. The effects of environmental regulation and technical progress on $\mathrm{CO}_{2}$ Kuznets curve: An evidence from China. Energy Policy 77, 97-108.

You, S., Cheng, S., Yau, H., 2009. The impact of textile industry on China's environment. International Journal of Technology and Design Education 2 (1), 33 -43.

Yu, D., Shi, P., Liu, Y., Xun, B., 2013. Detecting land use and water quality relationships from the view point of ecological restoration in an urban area. Ecological Engineering 53, 205216.

Zhang, W., Li, H., Sun, D., Zhou, L., 2012. A statistical assessment of the impact of agricultural land use intensity on regional surface water quality at multiple scales. International Journal of Environmental Research and Public Health 9, 4170-4186.

Zhao, J., Lin, L., Yang, K., Liu, Q., Qian, G., 2015. Influences of land use water quality in a reticular river network area: a case study in Shanghai China. Landscape and Urban Planning 137, 20-29.

Zhao, X., Zhao, Y., Zeng, S., Zhang, S., 2015. Corporate behavior and competitiveness: impact of environmental regulation on Chinese firms. Journal of Clenaer Production 86, 311-322. 